\title{
Baseline survey: Summary report of district Lasbela
}

Pakistan Initiative for Mothers and Newborns (PAIMAN)

Follow this and additional works at: https://knowledgecommons.popcouncil.org/departments_sbsr-rh

Part of the Family, Life Course, and Society Commons, and the Maternal and Child Health Commons How does access to this work benefit you? Let us know!

\section{Recommended Citation}

Pakistan Initiative for Mothers and Newborns (PAIMAN). 2006. "Baseline survey: Summary report of district Lasbela." Islamabad: Population Council. 


\section{Baseline Survey \\ Summary Report}

District Lasbela

\section{Introduction}

This summary report presents some of the key findings of a 2005 baseline household survey in Lasbela district, one of the ten districts in Pakistan that are the focus of the PAIMAN project. The Pakistan Initiative for Mothers and Newborns (PAIMAN) is a five-year project funded by the United States Agency for International Development (USAID). PAIMAN is committed to assist the Government of Pakistan in its implementation of the full spectrum of interventions necessary to address maternal and neonatal health $(\mathrm{MNH})$ issues. The PAIMAN district survey results are presented individually; the districts are: Rawalpindi, Jhelum, Khanewal and DG Khan in Punjab; Dadu and Sukkur in Sindh; Jaffarabad and Lasbela in Balochistan; and Upper Dir and Buner in North West Frontier Province.

PAIMAN has developed a monitoring and evaluation plan to ensure that the success of the project was properly ascertained, and that the appropriate lessons learned. PAIMAN conducted the baseline household survey in the ten districts in order to understand local $\mathrm{MNH}$ perceptions and practices. The study population included all currently married women of reproductive age (15-49 years) living in all urban and rural areas of the district. The sampling design was a stratified, systematic sample of households.

In Lasbela, 986 women were interviewed for the study, of whom 643 (65 percent) were rural. Fewer than 10 percent of respondents were literate. On average, respondents had borne 3.8 children, of whom 3.5 were still living. 


\section{Knowledge,}

\section{Attitude}

\section{and Behavior}

Figure 1: Percentage of married women in Lasbela who know at least 3 danger signs

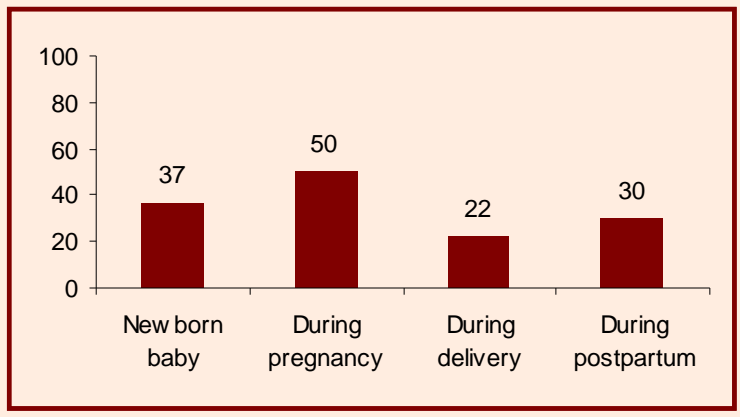

Figure 2: Percentage of married women in Lasbela who received antenatal care, TT injections and iron folate during their last pregnancy

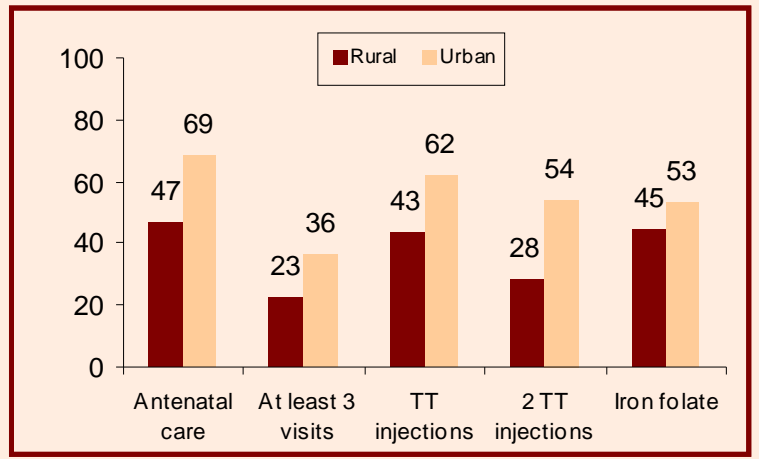

Figure 3: Percentage of married women in Lasbela who received antenatal services during their antenatal visits, by type of services

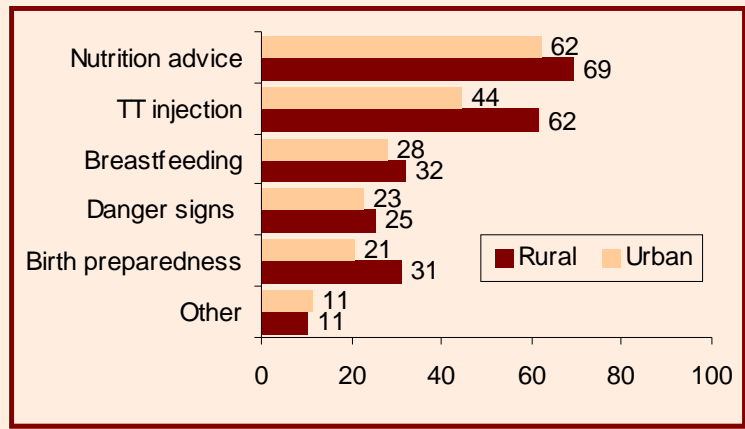

\section{Some Women Know Danger Signs Well}

\section{Knowledge of danger signs}

Only a small proportion of married women recognize three or more danger signs during pregnancy, during delivery, in the postpartum period, and in newborns (figure 1).

\section{Source of information regarding danger signs}

* Most receive information from their in-laws, family members and friends.

* About 4 percent indicate that they receive information primarily from television.

* Only 9 percent in rural areas indicate that Lady Health Workers are their source.

* District/Tehsil Headquarter Hospitals are also a source for about 9 percent in rural areas and 21 percent in urban areas.

\section{Most Women Receive Antenatal Care}

* Over 84 percent consider it necessary for women to receive antenatal check-ups.

* Most believe that an antenatal check-up should occur after the first trimester of pregnancy, or whenever necessary

* For their last pregnancy (figure 2), 47 percent of rural and 69 percent urban women had an antenatal check-up, but only 23 percent rural and 36 percent urban had 3 or more.

* Over 62 percent urban and 43 percent rural had TT injections during their last pregnancy, but only 28 percent rural and 54 percent urban had 2 TT shots.

* Less than half took iron folate tablets during their last pregnancy.

\section{Components of antenatal check-up}

Figure 3 indicates while most women are advised about nutrition and TT injections, they are not advised about preparing for emergencies.

\section{Few Women Prepared for Emergencies; Most Deliver at Home}

\section{Preparedness for childbirth}

Figure 4 shows that most women prepare clothes for their baby, most do not appear to have made appropriate arrangements for delivery

\section{Place of delivery and services}

* A majority ( 85 percent) agree that delivery services should be obtained from skilled birth attendants.

* Data obtained on births that occurred during the last three years, show that 89 percent of rural and 52 percent of urban women delivered their babies at home (figure 5).

* Twenty-five percent of deliveries were conducted by a skilled birth attendant.

\section{Delivery characteristics}

From figure 6, almost 93 percent of rural and 89 percent of urban respondents indicate they had a normal vaginal delivery. 


\section{Complications During Pregnancy and Childbirth are Common}

Three-quarters of urban and rural pregnant women indicate they experienced a complication during their last pregnancy. Severe headache, high fever and severe abdominal pain were the complications most reported.

Six in every 10 women report experiencing at least one complication during delivery (66 percent rural; 48 percent urban). About 40 percent rural and 34 percent urban areas report experiencing excruciating pain during their last pregnancy. A quarter of women in rural and 14 percent in urban areas suffered bleeding before labor began. Excessive bleeding, prolonged labor and fever are among other reported complications.

For many of these complications, women receive no care or inappropriate care.

\section{Postpartum and Newborn Care Need Attention}

\section{Postpartum check-up}

* In rural Lasbela, more than 59 percent feel that postnatal care is necessary, compared to 63 percent in urban areas. Married women are often not aware of the complications that can arise following birth, and may ignore the symptoms.

* For those who delivered their last baby at home, 80 percent did not receive any postnatal check-ups.

* Among those who go for postnatal care, 18 percent go within 24 hours after childbirth.

\section{Immediate care of newborn}

* While some mothers (20 percent) report that their newborns are put with them immediately following delivery, a large percent indicate that their newborns are placed on either a piece of cloth or on a mattress $(77$ percent urban; 56 percent rural).

* About 14 percent in rural areas indicate that their newborns are placed on the floor immediately after delivery.

* Almost 84 percent of the babies are given a bath within one hour of birth; only 3 percent are bathed after the recommended six hours.

\section{Colostrum and breastfeeding}

Almost all of the newborns are given breast milk. In rural areas, 86 percent state that they give colostrum to their babies; 93 percent do so in urban areas. Of those who gave colostrum to their newborns, 6 percent gave it within the first hour after birth.

\section{Neonatal care}

* For the last live child born, only 16 percent of rural and one-fourth of urban report that the newborn was examined by a skilled provider. Fever and difficult breathing were the problems most often noted at birth; shivering and watery stools were most commonly noted within the first seven days.

* The most common choice for children's treatments in Lasbela is private hospitals/clinics (32 percent rural; 54 percent urban).

* No external treatment was sought for reported symptoms in 43 percent of rural cases and 25 percent urban.

\section{Clean Delivery Practices}

Respondents who delivered their last child at home report the following delivery practices:

* TBA did not wash her hands with soap for 21 percent of rural and 12 percent of urban deliveries.

* TBAs did not use a new blade for cutting the cord for at least 12 percent of rural deliveries and at least 7 percent urban. In urban areas, scissors and knives were sometimes used by TBAs.

- A new piece of thread was used for tying the cord for 95 percent of urban deliveries and 92 percent of rural deliveries.

Figure 4: Percentage of married women in Lasbela who made delivery arrangements, by type of arrangement

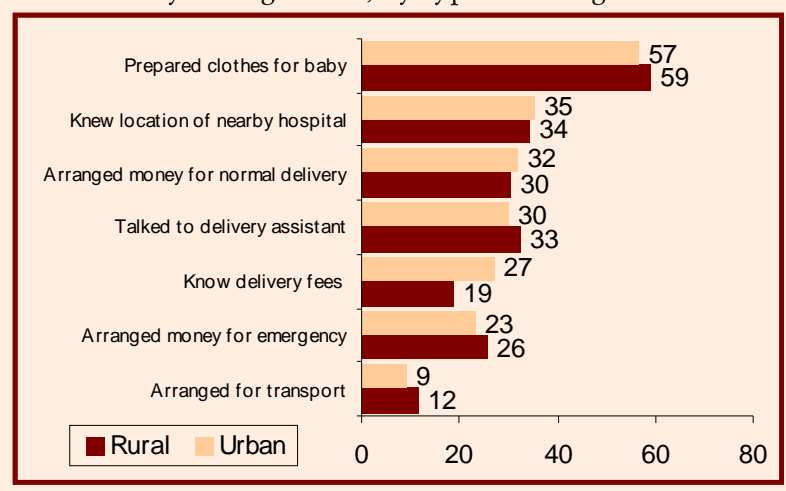

Figure 5: Percentage of married women in Lasbela who gave birth in the preceding three years, by place of delivery

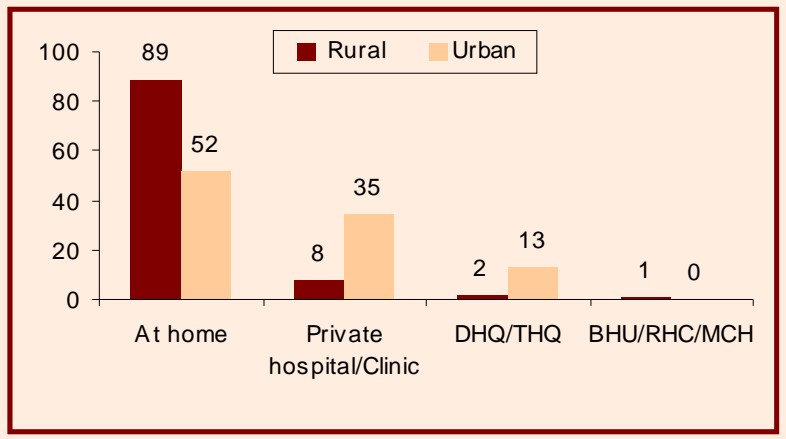

Figure 6: Percentage of married women in Lasbela who gave birth, by type of last delivery

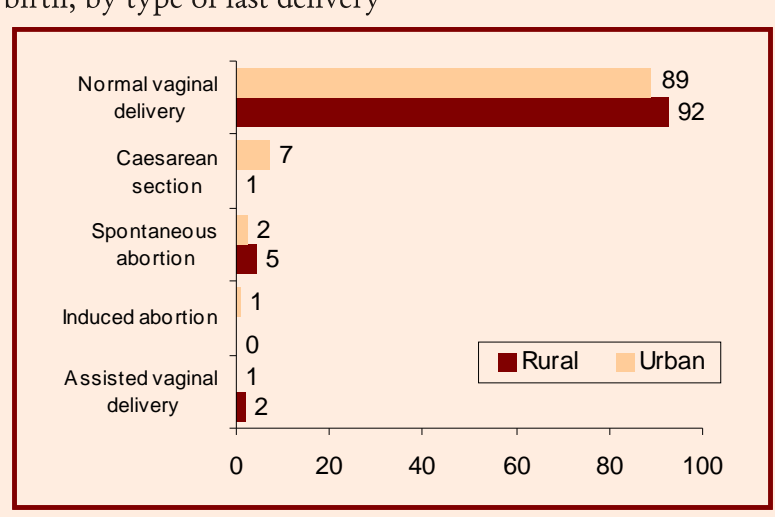




\section{Three Delays}

Delays in deciding to seek care, in reaching adequate health facilities, and in receiving appropriate care at health facilities lead to most maternal deaths.

\section{First delay: decisions must be made quickly}

* Women are neither prepared for delivery (figure 4) nor aware of danger signs (figure 1), so are not well placed to make emergency decisions.

* Husbands are the main decision makers (74 percent) for emergency deliveries.

\section{Second delay: transport must be at hand and available}

- Of those who seek treatment for delivery complications, 54 percent use own transport or private transport to reach the health facility.

* The average waiting time for transport is 60 minutes.

* Transport averages 60 minutes to reach the desired facility, but in 18 percent of deliveries, it took more than two hours.

\section{Third delay: emergency services must be ready}

* After reaching the health facility, almost 83 percent of women report receiving services within 30 minutes. The median waiting time was 20 minutes.

* Appropriateness and quality of those services could not be ascertained.

\section{Access to media}

Only 6 percent of women in rural areas (figure 7) watch television, compared to almost half in urban areas. A majority, both rural and urban, do not listen to the radio and almost none reads a newspaper. About 29 percent of the population in Lasbela has access to some sort of media, whether it is television, radio or newspapers.

Figure 7: Percentage of married women in Lasbela who have access to mass media, by type of media

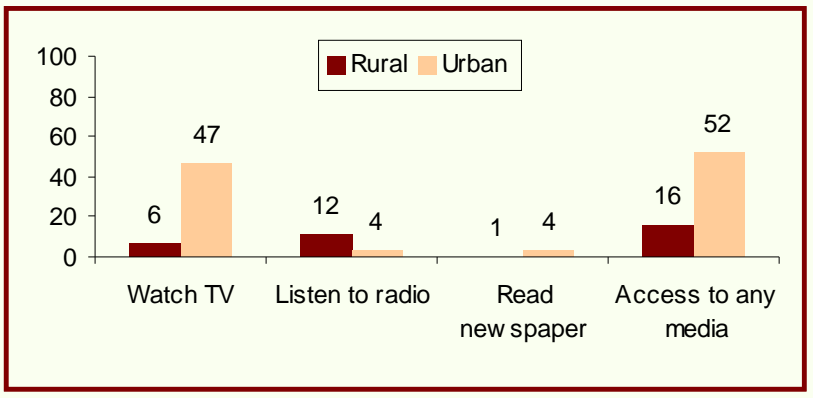

\section{Many pregnancies are unwanted}

* Ten percent of respondents were using family planning at the time of the study; pills and female sterilization were the methods most commonly used. Eleven percent said they would like to use in the future.

* Thirteen percent reported that their last pregnancy was unwanted or mistimed. If unwanted pregnancies could be prevented in the first place, attendant morbidity and mortality could be avoided.

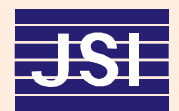

JSI Research \& Training Institute, Inc.

CA \# 391-A-00-05-01037-00 project is funded by the United States Agency for International Development

and implemented by JSI Research \& Training Institute, inc. in conjunction with Aga Khan University, Contech International,

Greenstar Social Marketing, Johns Hopkins University/CCP, PAVHNA, The Population Council, and Save the Children USA. 